\title{
RAZPRAVE
}

\section{DRUŽBENI VPLIVI PRIREDITEV V MESTNI OBČINI KOPER}

\author{
AVTORICI \\ Kristina Jerman \\ Glem 5, SI - 6273 Marezige, Slovenija \\ pusnik.kristina@gmail.com
}

\section{dr. Ksenija Vodeb}

Univerza na Primorskem, Fakulteta za turistične študije - Turistica, Obala 11a, SI - 6320 Portorož, Slovenija

ksenija.vodeb@fts.upr.si

DOI: $10.3986 / G V 90102$

UDK: 911.3:338.48(497.472Koper)

COBISS: 1.01

\section{IZVLEČEK}

\section{Družbeni vplivi prireditev v Mestni občini Koper}

Družbeni vplivi prireditev so že več kot dve desetletji pogosta tema raziskovalcev, vzadnjem času tudi vdomači znanstveni literaturi. V zadnjih letih je v Mestni občini Koper opaziti velik poudarek na prireditvah, zato v pričujočem delu preučujemo njihov družbeni vpliv. Osnovni cilj prispevka je bil preučiti družbene vplive prireditev $v$ luči zaznav lokalne skupnosti. V maju in juniju 2017 smo izvedli anketo med lokalnimi prebivalci in poglobljene strukturirane intervjuje s predstavniki treh krajevnih skupnosti ter predstavnico občine. Rezultati so pokazali, da lokalna skupnost podpira razvoj prireditev, da prireditve oživljajo dogajanje v mestu in spodbujajo razvoj turizma, s poudarkom na strateškem razvoju in sodelovanju vseh deležnikov.

\section{KLJUČNE BESEDE}

turizem, turistični vplivi, prireditve, destinacija, lokalna skupnost, Mestna občina Koper

\section{ABSTRACT}

\section{Social impacts of events in Municipality of Koper}

The social impacts of events have been a frequent topic for researchers for over two decades, recently also in domestic scientific literature. In recent years, the Municipality of Koper has put a greater emphasis on social events, so our goal was to study their social impacts. The aim of this article was to examine the social impacts of events in the light of the perceptions of the local community. In May and June 2017, we conducted a survey among the local residents and an in-depth structured interview with representatives of three local communities and a representative of the Municipality. The results showed that the local community supports the development of events; that the events revive the city atmosphere and enhance the development of tourism with an emphasis on the strategic development and participation of all stakeholders.

\section{KEY WORDS}

tourism, tourism impacts, events, destination, local community, Municipality of Koper

Uredništvo je prispevek prejelo 11. januarja 2018. 


\section{Uvod}

Turizem v zadnjih desetletjih še zdaleč ne pomeni samo potovanje v želeno destinacijo in ogled tamkajšnjih zanimivosti. Vedno bolj je izražena tudi globlja, čustvena in doživljajska plat potovanja. Turisti želijo doživeti pristnost destinacije, $\mathrm{k}$ temu pa lahko v veliki meri prispevajo lokalne prireditve. Yürük s sodelavci $(2017,367)$ ugotavlja, da se generalno gledano število prireditev povečuje. Goldblatt (2000) in Yuan (2013) sklepata, da rastoče število prireditev postaja globalni fenomen. Glede na to, da turistični tokovi niso vedno enakomerno razporejeni skozi leto - v sezonah je turistične in gostinske zmogljivosti lažje zapolniti, težave pa so pogosto $\mathrm{v}$ času izven sezon $-\mathrm{v}$ tem primeru delujejo prireditve kot turistična privlačnost destinacije za obisk ali podaljšanje obiska. Nekateri avtorji so prepričani, da so prireditve učinkovit način za obvladovanje vrzeli v izven sezonskem času za destinacijo (Connell, Page in Meyer 2015). V domači literaturi zasledimo nekatere pomembne študije s področja preučevanja družbenih vplivov na primeru velikih športnih prireditev (Lesjak, Podovšovnik in Uran Maravić 2014), zadovoljstva s kakovostjo bivalnega okolja (Koderman 2014) in zadovoljstva $z$ življenjem prebivalcev (Medarić 2014) na istem obravnavanem območju.

Goldblatt (v: Watt 1998, 1) prireditev definira kot edinstven čas z obredom in rituali, z namenom, da zadovolji specifične potrebe. Podobno jo definira tudi Watt $(1998,10)$ kot nadpomenko posebnim ritualom, predstavitvam, nastopom ali praznovanjem, ki so zavestno načrtovani ali ustvarjeni za posebne priložnosti s tem, da se zadovoljijo družbeni, kulturni in/ali korporacijski cilji. Sam mednje šteje nacionalna praznovanja, pomembne državljanske priložnosti, unikatne kulturne nastope, velike športne prireditve, korporacijske funkcije ter promocijo in prodajo raznih produktov (Watt 1998). Tudi Shone in Parry $(2010,4)$ jih definirata kot fenomen, ki ima prostočasne, kulturne, osebne in organizacijske cilje, izven dnevnih aktivnosti, čigar namen je razsvetliti, praznovati, zabavati ali omogočiti doživetje. Getz $(1997,4)$ je mnenja, da je vsaka prireditev edinstvena kombinacija trajanja, izvedbe, menedžmenta in obiskovalcev. Hkrati pa poudari, da je nemogoče splošno opredeliti prireditve in njih vrste. Gre predvsem za poglede avtorjev iz različnih zornih kotov. Zaradi tega same prireditve na podlagi konteksta opredeli skozi dva vidika (Getz 1997):

- za organizatorje je prireditev neponovljiva in občasna izkušnja, ki se zgodi izven rednih aktivnosti, programa naročnika ali organizacijskega telesa,

- za obiskovalca ali gosta je prireditev priložnost za prostočasno, družbeno in kulturno doživetje izven vsakodnevnih obveznosti.

Sikoškova $(2010,17)$ sklene, da je prireditev edinstvena, vnaprej zamišljena, načrtovana, organizirana in skrbno izpeljana aktivnost, sestavljena iz vrste posameznih dogodkov. Watt (1998) poudari, da je razvrščanje prireditev težavno. Poda primer medijske pozornosti in pokritosti prireditve, ki med prireditvami zelo niha. Prav tako so velike razlike v smislu vloženih sponzorskih sredstev in drugih dejavnikov. Zaradi te vsestranskosti veliko avtorjev prireditve deli na različne načine, na primer po velikosti, obliki oziroma vsebini in namenu.

Ne glede na to, ali je prireditev načrtovana ali nenačrtovana, je lahko na koncu uspešno ali neuspešno izpeljana. V čem je torej razlika? McDonnell, Allen in O’Toole (1999) vidijo ključ do upeha v dobrem sodelovanju z vsemi deležniki v procesu načrtovanja in izvedbe prireditve. Velja namreč, da zadovoljno občinstvo ali zadovoljen organizator ne pomeni nujno uspešne prireditve. Uspešnost naj se torej meri z zadovoljstvom vseh deležnikov v procesu. To so (McDonnell, Allen in O’Toole 1999) lokalne organizacije, lokalna skupnost, sponzorji, mediji, sodelujoči in obiskovalci. Razmerja, ki se ustvarjajo med organizatorji, lokalno skupnostjo in obiskovalci, so zelo kompleksna. Vpliv na lokalno okolje je lahko pozitiven ali negativen, lahko pa oboje hkrati, odvisno od zornega kota deležnika. Različni dejavniki različno vplivajo na odnose med deležniki. Derret (v: Robinson, Wale in Dickson 2010, 15) meni, da je uspešnost prireditve v veliki meri odvisna od odnosov med deležniki. Bowdin s sodelavci (2011) pa poudari pomen organizacije prireditev ne samo za turiste, temveč tudi za domačine. Brez vključevanja in sprejemanja domačinov so take prireditve obsojene na propad, saj izgubljajo pristnost in privlačnost. 
Kot zapiše Bowdin s sodelavci $(2011,79)$ se prireditve ne odvijajo v vakuumu, ampak se dotikajo vseh vidikov našega življenja, s čimer želi povedati, da prireditve s seboj prinašajo pozitivne in negativne posledice, kar se kaže v naravnem in družbenem okolju. Torej so vplivi sprememba, ki se je zgodila v nekem času in je posledica nekega dogodka (Hall in Lew 2009, 54). Tako so lahko isti vplivi na enem področju pozitivni, na drugem pa negativni. Vplive lahko delimo na različne načine. Bowdin s sodelavci (2011) jih deli na turistične in ekonomske, družbeno-kulturne, fizične in okoljske ter politične. Shone in Parry (2010) jih delita na družbene, politične, ekonomske in razvojne. Yörük, Akyol in Şimşek (2017) pa jih delijo na ekonomske, družbene, kulturne, okoljske in politične. Čeprav so delitve različne, gre pri vseh za vplive, ki jih povzročajo prireditve, le pojmovanje je drugačno. Jones (2001) poudari, da vplivi ne nastajajo samo po prireditvi, temveč tudi pred in med prireditvijo. Tosun (2002) pa izpostavi, da vplivi niso splošni, ampak so odvisni od razvojne stopnje destinacije.

Brown s sodelavci (2015) je analiziral raziskave s področja vplivov prireditev in ugotovil, da jih je s področja ekonomskih vplivov občutno več kot tistih s področja družbenih ali okoljskih. Do istih zaključkov so prišli tudi Kariel in Kariel (1982) ter Zhou in Ap (2009). Razlog je iskati v temu, da organizatorje in sponzorje prireditev najbolj zanima, ali se je finančni vložek obrestoval. Prav tako so ti podatki lažje merljivi, saj so kvantitativne narave. Kariel in Kariel (1982) vidita razlog v dejstvu, da gre pri prireditvah za razmeroma nov pojav, zaradi česar se kaže pomanjkanje podatkov, informacij in znanja. Nekaj raziskav s področja družbenih in okoljskih vplivov je sicer zaznati. Ena takih je raziskava Anderssona in Lundberga (2013), kjer sta avtorja poskušala izmeriti družbene in okoljske vplive na kvantitativen način, z uporabo spremenljivk kot sta kupna moč in ekološki odtis. Toda Sharpley (2014) svari, da družbene vplive ne moremo izmeriti predvsem s kvantitativnimi pristopi, saj gre za vplive, ki se odražajo na odnosih in različnih ravneh, kar pomeni, da jih je treba obravnavati celostno in poglobljeno. Balduck, Maes in Buelens (2011) opredelijo družbene vplive kot nekaj kar turizem spreminja v smislu skupinskega in individualnega sistema vrednot, vzorcev vedenja, strukture skupnosti, življenjskih stilov in kakovosti življenja. McDonnell, Allen in O’Toole (1999) ugotavljajo, da imajo prireditve neposredne družbene in kulturne vplive na obiskovalce in širšo lokalno skupnost. To se kaže predvsem v zabavnem doživetju, preko katerega se povečuje ponos na destinacijo in kulturna zavest prebivalcev. Prireditve omogočajo delitev in izmenjavo izkušenj, krepitev sodelovanja in oživljanje tradicije. Prireditve povzročajo tudi negativne posledice, kot je prekomerno uživanje alkohola in mamil ter povečana stopnja kriminala. Slabo organizirane prireditve imajo lahko širše posledice na družbeno življenje in strukturo skupnosti. Med drugim to vključuje rast cen dobrin in storitev, kar vpliva predvsem na socialno šibke skupine. Getz (1997) opozarja, da je treba $\mathrm{v}$ organizacijo prireditev vključiti lokalno prebivalstvo, saj lahko sicer pride do negativnih vplivov, ki se kažejo kot odtujevanje lokalne skupnosti. Robinson, Wale in Dickson (2010) izpostavijo, da vsi vplivi niso vselej vidni in se razlikujejo po stopnji moči. Kot izhaja iz zgornjih navedb, vplivi prireditev vsekakor so, vendar ni dovolj vedeti za njih, če jih ne raziščemo, razumemo in ovrednotimo, saj jih le tako lahko upravljamo in načrtujemo. To je naloga menedžmenta, ki vplive lahko obravnava na tri načine, o čemer so razpravljali Mason (2003), Hall in Lew (2009) ter Vodebova (2014):

- PASIVNO: Menedžment zaznava, prepoznava in ugotavlja vplive. Odzivni čas je zamujen, vplivi se $\mathrm{v}$ prihodnje ponavljajo.

- AKTIVNO: Menedžment se poglobi v vplive in začenja razumevati, da zaznave domačinov niso vplivi, temveč je treba preučiti njihov odnos do njih, da bi jih razumeli. Odzivni čas je krajši, vplivi se v prihodnje ponavljajo v manjši meri.

- PROAKTIVNO: Menedžment razume, da ima moč upravljanja vplivov na način, da jih opazuje, spremlja, predvideva, načrtuje in usmerja. Njegova vloga ni več opazovalna, temveč so njegovi odzivi v naprej načrtovani. Z zavestnim spreminjanjem delovanja dosega želene spremembe vplivov.

V pomanjkanju teoretičnih podlag s področja družbenih vplivov prireditev vidimo priložnost za prispevek k razvoju novih spoznanj. Ta so pomembna, saj je zaznana rast števila prireditev predvsem po letu 2008 (Getz in Page 2016), zaradi česar je potrebna večja pozornost, da ne pride do degradacije okolja prireditvene regije in njene lokalne skupnosti. 


\section{Metodologija in opis vzorca}

Empirična raziskava je zajela preučevanje odnosa domačinov, predstavnikov krajevnih skupnosti in predstavnice občine do prireditev v Mestni občini Koper. Raziskava je bila dvojna, pri čemer smo uporabili anketni vprašalnik za domačine kot kvantitativni pristop raziskovanja ter poglobljen strukturiran intervju kot kvalitativni pristop s predstavniki treh od dvaindvajsetih krajevnih skupnosti in predstavnico občine. Na tak način smo želeli zagotoviti reprezentativnost vzorca, saj smo družbene vplive ocenili iz treh zornih kotov. Razlika med zornimi koti izbrane populacije se kaže predvsem v pričakovanih interesih in motivih za sodelovanje oziroma izvedbo prireditev. $\mathrm{Z}$ uporabo obeh metod smo ugotavljali zaznave izbrane populacije, vezano na prireditve v občini z vidika lokalne skupnosti. Raziskava je potekala med 24. majem in 30. junijem 2017.

Osnovo za anketni vprašalnik je v večji meri prispeval že preizkušen instrument Goriškove (2015), ki se je ukvarjala $\mathrm{z}$ analizo družbeno-kulturnih vplivov ladijskega turizma v Sloveniji. Za namen te raziskave pa je bil vprašalnik $\mathrm{z}$ avtoričinim pisnim dovoljenjem ustrezno prirejen. Goriškova $(2015,48)$ je svoj vprašalnik oblikovala na podlagi del: Fredlin, Deery in Jago (2006, 28-32), Wilson s sodelavci (2015, 58-65) ter Schlenker, Foley in Getz (2010, 24-28). Vprašalnik je bil razdeljen med 300 prebivalcev občine. Število prejetih, povsem izpolnjenih anket je bilo 200 , kar predstavlja $0,47 \%$ vseh prebivalcev občine, starejših od 18 let. Starostna in spolna struktura vzorca ustreza odstotnim vrednostim starostne in spolne strukture vseh prebivalcev starejših od 18 let (Statistični urad Republike Slovenije 2017). To smo zagotovili zato, da bi bili naši rezultati zanesljivejši, saj jih tako lažje posplošimo. Ob pridobivanju izpolnjenih vprašalnikov smo sproti beležili razporejenost anketirancev glede na spol in starost. Te skupine so se ustrezno polnile, zato ni bilo potrebe po dodatnem iskanju določenega profila anketiranca.

Med anketiranci so bile ženske (51\%) v rahli prednosti pred moškimi (49\%). Slednji so bili po večini v starostnih skupinah med 30-39, ter 40-49 let, medtem ko je bilo največ žensk v starosti nad 70 let, sledile pa so jim tiste med 30 in 39 let. Največ anketirancev $(69,5 \%)$ živi v predmestjih občine, iz zaledja jih je $23 \%$, iz centra mesta pa $7 \%$. V občini živijo v povprečju 37 let. Največ jih je zaposlenih ali samozaposlenih $(60,5 \%)$ ter upokojencev (28\%). Po večini imajo zaključeno srednješolsko izobrazbo $(48,5 \%)$.

$\mathrm{V}$ anketnem vprašalniku je bilo treba podati prvo miselno povezavo na prireditev $\mathrm{v}$ občini, nato pa pozitivne in negativne plati prireditev, $s$ katerimi smo želeli zajeti največkrat zaznane vplive s strani domačinov. Želeli smo ugotoviti najbolj prepoznavno prireditev med domačini. Sledilo je vprašanje o pogostosti obiskovanja prireditev in osebne vključenosti pri prireditvah, s katerimi smo želeli preveriti razliko v zaznavah med prebivalci, ki so vključeni v proces prireditve, in tistimi, ki so zgolj obiskovalci. Želeli smo tudi oceniti splošen odnos prebivalcev do prireditev. Ob koncu prvega dela vprašalnika je bilo šest demografskih vprašanj, s katerimi smo želeli orisati tipičnega prebivalca, ki rad obiskuje prireditve, in takega, ki ne. Zadnje vprašanje je bilo sestavljeno iz 27 trditev o družbenih vplivih, te so v predhodnih raziskavah zaznali Yörük, Akyol in Şimşek $(2017,372)$ ter Zhou in Ap (2009, 82). Anketirance smo prosili, da ocenijo, v kolikšni meri se strinjajo s trditvami po petstopenjski Likertovi lestvici, pri čemer je 1 pomenilo najnižjo stopnjo strinjanja in 5 najvišjo stopnjo strinjanja. Pridobljene odgovore smo obdelali s pomočjo statističnega paketa SPSS 17.0.

Za namene raziskave smo opravili tudi štiri intervjuje, in sicer s predstavnico Turistične organizacije Koper in s predstavniki treh krajevnih skupnosti v občini. Vsi intervjuji so bili strukturirani, kar pomeni, da anketar v neposrednem stiku $\mathrm{z}$ vprašancem uporablja vnaprej do potankosti izdelan vprašalnik in postavi $v$ načelu vsem ista vprašanja na enak način, poleg tega pa je nastop premišljen in standardiziran (Mesec 1998, 82). Mesec (1998) kot pomanjkljivost omenjenega tipa intervjuja navede, da včasih pride do popačenosti odgovorov, saj so vprašani nekoliko omejeni pri izražanju svojega mnenja na določeno vprašanje. Hkrati pa poudari, da tak način spraševanja zagotavlja primerljivost odgovorov in posledično tudi lažjo kasnejšo obdelavo in analizo s pomočjo kvantitativnega pristo- 
pa (Mesec 1998). Torej gre za nekakšno mešanico kvalitativne metode spraševanja, katere odgovori so lahko obdelani na kvantitativen način. To je tudi razlog, zakaj smo se odločili za uporabo takšnega intervjuja.

Med krajevnimi skupnostmi vključenimi v raziskavo so bile krajevne skupnosti Koper-center, OlmoPrisoje in Boršt. Gre za krajevne skupnosti v centru mesta, v predmestju in zaledju. S tem smo si obetali pridobiti širši vpogled v odnos skupnosti in doseči lažje posploševanje rezultatov, hkrati pa doseči boljšo zastopanost obravnavanih skupin respondentov. Predsednike krajevnih skupnosti smo za namen intervjuja najprej elektronsko kontaktirali, nato je sledil dogovor za srečanje in intervju. Intervjuji so potekali od začetka do polovice junija približno 30 minut na dogovorjeni lokaciji. Ker smo želeli pridobiti širši vpogled v zaznave respondentov glede prireditev v občini, smo se obrnili tudi na predstavnico občine, vodjo Turistične organizacije Koper. Intervjuvanko smo kontaktirali po elektronski pošti in priložili vprašanja, saj je izrazila željo po pisnem odgovarjanju. Vprašanja za vse tri predstavnike krajevnih skupnosti so bila enaka. Pogovor smo začeli o sodelovanju z občino, nadaljevali pa z zaznavanjem interesa prebivalcev njihove skupnosti pri sodelovanju na prireditvah. Nato smo se osredotočili na zaznane koristi in slabosti prireditev znotraj njihove skupnosti. V zadnjem delu nas je zanimal njihov pogled na prihodnji razvoj prireditev v občini. Predstavnico občine smo vprašali o vlogi Turistične organizacije Koper pri organizaciji prireditev. Sledila so vprašanja o sodelovanju s krajevnimi skupnostmi, zaznanem interesu občanov pri sodelovanju na prireditvah, mnenju o obstoječih prireditvah, koristih in slabostih ter možnostih za nadaljnji razvoj prireditev.

\section{Rezultati}

\subsection{Anketa}

Prva miselna povezava anketirancev na prireditev je bila Koprska oziroma Rumena noč ter dogajanje, vsaka s frekvenco (f) 21. Sledila sta jima gneča $(f=19)$ in zabava $(f=17) .11$ odgovorov se je nanašalo na druženje. Po mnenju večine anketirancev prinašajo prireditve druženje $(\mathrm{f}=49)$ in zaslužek $(\mathrm{f}=24)$. $\mathrm{Na}$ tretjem mestu po pogostosti odgovorov smo zabeležili turizem $(\mathrm{f}=21)$. Sledila sta oživljanje mesta $(\mathrm{f}=13)$ ter zabava $(\mathrm{f}=12)$. Presenetljiva so bila mnenja, da negativnih plati prireditev ni $(\mathrm{f}=48)$. Kot negativne plati prireditev so se izkazali: hrup $(\mathrm{f}=34)$, gneča $(\mathrm{f}=31)$, smeti $(\mathrm{f}=14)$ in težave s parkirnimi mesti $(\mathrm{f}=12)$. Anketiranci so kot najbolj prepoznavni prireditvi omenili prireditev Koprska oziroma Rumena noč $(\mathrm{f}=74)$ in Sladka Istra $(\mathrm{f}=56)$. Obe tvorita $65 \%$ odgovorov v tem sklopu. 11 jih je navedlo Fešto kalamarov. Glede pogostosti obiskovanja prireditev jih večina na leto obišče nekaj. To velja za več kot polovico vseh anketiranih in gotovo ni razlike med odgovori glede na spol. Ugotavljamo tudi, da je majhna razlika med odgovori po spolu glede obiska ene do dveh prireditev letno. Nadalje smo se osredotočili na sodelovanje anketirancev na prireditvah in delo v povezavi s turizmom. Ugotovili smo, da jih sodeluje $7,5 \%$, torej 15 . Največ jih sodeluje kot nastopajoči $(f=5)$, kot ponudnik $(f=4)$ ali organizator $(\mathrm{f}=1)$. Le 25 anketirancev se je izreklo, da delajo v turizmu. Sledilo je vprašanje o osebnem mnenju glede prireditev v občini. Ugotovili smo, da večina anketirancev (59\%) rada obiskuje prireditve in si želi, da bodo organizirane tudi v prihodnje. Bistvenih razlik v odgovorih med spoloma ni. Na drugem mestu (27\%) so tisti, ki prireditve podpirajo, vendar se jih ne udeležujejo. Nekaj anketirancev je odgovorilo, da nima posebnega mnenja o prireditvah. Zgolj 6 jih odkrito nasprotuje prireditvam.

$\mathrm{V}$ preglednicah 1 in 2 predstavljamo rezultate ocenjenih trditev o družbenih vplivih prireditev. Sklop trditev smo za potrebe analize razdelili na pozitivne (16) in negativne (11) vplive. Iz preglednice 1 je razvidno, da so se anketiranci $z$ vsemi pozitivnimi trditvami nadpovprečno strinjali $(M>3)$. V povprečju so se najbolj strinjali s trditvijo, da prireditve oživljajo dogajanje $(M=4,33)$ in da spodbujajo razvoj turizma $(M=4,16)$. Najmanj pa so se v povprečju strinjali s trditvijo, da prireditve spodbujajo razvoj in kakovost javnih služb $(M=3,16)$. 
Iz preglednice 2 je razvidno, da so se anketiranci nadpovprečno strinjali s skoraj vsemi negativnimi trditvami $(M>3)$. Pod povprečjem sta označeni le trditvi, da se zaradi prireditev prebivalstvo umika iz mesta $(M=2,47)$ ter trditev, da je zaradi prireditev več kriminala $(M=2,7)$. V povprečju so se najbolj strinjali s trditvami, da je težje dobiti parkirno mesto $(M=4,15)$, da je več gneče na javnih površinah in objektih $(M=4,14)$ ter da je zaradi prireditev več prometne gneče $(M=4,09)$. Največji del anketirancev se je strinjal, da je zaradi prireditev več hrupa, odpadkov, prekomernega pitja alkohola in uživanja mamil, prometne gneče, da je težje najti parkirno mesto, da je več gneče na javnih površinah in objek-

Preglednica 1: Pozitivni vplivi.

\begin{tabular}{|c|c|c|c|c|c|c|c|}
\hline Trditev & $1(\%)$ & $2(\%)$ & $3(\%)$ & $4(\%)$ & $5(\%)$ & $\begin{array}{l}\text { aritmetična } \\
\text { sredina }\end{array}$ & $\begin{array}{l}\text { standardni } \\
\text { odklon }\end{array}$ \\
\hline $\begin{array}{l}\text { Zaradi prireditev sem ponosen/-na } \\
\text { mesto Koper. }\end{array}$ & 6 & 6 & 20 & 42 & 26 & 3,76 & 1,09 \\
\hline $\begin{array}{l}\text { Prireditve spodbujajo spoznavanje } \\
\text { novih ljudi in izkušenj. }\end{array}$ & 3,5 & 3 & 9 & 53,5 & 31 & 4,05 & 0,91 \\
\hline $\begin{array}{l}\text { Prireditve spodbujajo proizvodnjo in } \\
\text { prodajo lokalnih izdelkov/pridelkov. }\end{array}$ & 1 & 3,5 & 11,5 & 53,5 & 30,5 & 4,09 & 0,8 \\
\hline $\begin{array}{l}\text { Prireditve pripomorejo k ohranjanju } \\
\text { lokalne identitete. }\end{array}$ & 2,5 & 5,5 & 14,5 & 49 & 28,5 & 3,95 & 0,94 \\
\hline Prireditve spodbujajo razvoj turizma. & 1 & 3,5 & 11,5 & 46 & 38 & 4,16 & 0,84 \\
\hline $\begin{array}{l}\text { Obiskovalci prireditev povzročajo } \\
\text { večjo potrošnjo v lokalni skupnosti. }\end{array}$ & 2,5 & 10 & 23,5 & 41 & 23 & 3,72 & 1 \\
\hline $\begin{array}{l}\text { Zaradi prireditev je večja možnost } \\
\text { za zaposlitev lokalnih prebivalcev. }\end{array}$ & 7 & 16 & 32 & 36,5 & 8,5 & 3,23 & 1,05 \\
\hline Prireditve oživljajo dogajanje v Kopru. & 1 & 1 & 10 & 40 & 48 & 4,33 & 0,77 \\
\hline $\begin{array}{l}\text { Zaradi prireditev je Koper bolj } \\
\text { prepoznan na turističnem zemljevidu. }\end{array}$ & 3,5 & 4 & 15 & 54 & 23,5 & 3,9 & 0,93 \\
\hline $\begin{array}{l}\text { Prireditve v Koper privabljajo turiste } \\
\text { in obiskovalce iz Slovenije. }\end{array}$ & 0,5 & 2,5 & 12,5 & 56,5 & 27,5 & 4,09 & 0,74 \\
\hline $\begin{array}{l}\text { Prireditve v Koper privabljajo turiste } \\
\text { in obiskovalce iz tujine. }\end{array}$ & 3 & 12,5 & 30,5 & 43 & 11 & 3,46 & 0,95 \\
\hline $\begin{array}{l}\text { Prireditve spodbujajo vzdrževanje } \\
\text { in investicije v javne objekte. }\end{array}$ & 7 & 9 & 30 & 42 & 12 & 3,43 & 1,04 \\
\hline $\begin{array}{l}\text { Prireditve spodbujajo k obisku } \\
\text { kulturnih in naravnih zanimivosti. }\end{array}$ & 3,5 & 12,5 & 25,5 & 47,5 & 11 & 3,5 & 0,97 \\
\hline $\begin{array}{l}\text { Prireditve pripomorejo k zmanjšanju } \\
\text { družbenih predsodkov. }\end{array}$ & 4,5 & 15 & 36 & 39 & 5,5 & 3,26 & 0,94 \\
\hline $\begin{array}{l}\text { Zaradi prireditev je pestrejša in } \\
\text { bolj urejena infrastruktura za } \\
\text { šport in prosti čas. }\end{array}$ & 6 & 11,5 & 22,5 & 50 & 10 & 3,46 & 1,02 \\
\hline $\begin{array}{l}\text { Prireditve spodbujajo razvoj in } \\
\text { kakovost javnih služb. }\end{array}$ & 8,5 & 13 & 36,5 & 38,5 & 3,5 & 3,16 & 0,99 \\
\hline
\end{tabular}


tih ter da prireditve prispevajo k višanju cen dobrin in storitev. Odstotne vrednosti omenjenih odgovorov so se gibale med $40,5 \%$ in 53,5 \% znotraj posameznih trditev. Najbolj nevtralni so bili pri oceni, da so motena vsakdanja opravila domačinov ( $40 \%$ ) in da prireditve pripomorejo k višanju cen nepremičnin in stroškov najema ( $42 \%)$. Anketiranci se niso strinjali, da se zaradi prireditev prebivalstvo umika iz mesta ter da je zaradi prireditev več kriminala in sicer v prvem primeru $33 \%$, v drugem pa $32 \%$.

Za potrebe raziskave smo izračunali aritmetično sredino in standardni odklon vseh pozitivnih in negativnih trditev, ki smo jih s tem oblikovali v dve novi spremenljivki $\mathrm{z}$ imenoma pozitivni in negativni vplivi. Spremenljivka je lastnost enot (Knežević 2006, 33), aritmetična sredina je težišče vseh rezultatov (Knežević 2006, 74), standardni odklon pa je povprečje odklonov v neki množici vrednosti enot (Knežević 2006, 123). Pred nadaljnjimi koraki smo preverili še zanesljivost sklopa vseh 27 trditev o družbenih vplivih (ločeno za pozitivne in negativne), s pomočjo Cronbachovega alfa koeficienta. Zanesljivost podatka je njegova merska natančnost, njegova relativna sposobnost, da sporoča "resnično« vrednost opazovane enote na neki dimenziji (Knežević 2006, 19). Cronbachov alfa koeficient se uporablja za preverjanje zanesljivosti sklopa trditev $\mathrm{z}$ enako mersko lestvico, kot je v našem primeru Likertova. Njegova izračunana vrednost mora biti med 0,6 in 0,95 , da so trditve zanesljive. V našem primeru sta oba sklopa zanesljiva, saj sta njuni vrednosti 0,932 za pozitivne in 0,837 za negativne, prav tako pa je zanesljiv celoten sklop trditev o družbenih vplivih z vrednostjo 0,838 .

Preverili smo, če se dojemanje pozitivnih in negativnih vplivov razlikuje:

- med spoloma,

- po območjih bivanja v občini,

Preglednica 2: Negativni vplivi.

\begin{tabular}{|c|c|c|c|c|c|c|c|}
\hline Trditev & $1(\%)$ & $2(\%)$ & $3(\%)$ & $4(\%)$ & $5(\%)$ & $\begin{array}{l}\text { aritmetična } \\
\text { sredina }\end{array}$ & $\begin{array}{l}\text { standardni } \\
\text { odklon }\end{array}$ \\
\hline Zaradi prireditev je več hrupa. & 6 & 8 & 18 & 48,5 & 19,5 & 3,68 & 1,06 \\
\hline Zaradi prireditev je več odpadkov. & 4 & 7 & 14,5 & 46 & 28,5 & 3,88 & 1,03 \\
\hline $\begin{array}{l}\text { Zaradi prireditev so motena vsakdanja } \\
\text { opravila lokalnih prebivalcev. }\end{array}$ & 8,5 & 20,5 & 40 & 23,5 & 7,5 & 3,01 & 1,04 \\
\hline $\begin{array}{l}\text { Zaradi prireditev se lokalno } \\
\text { prebivalstvo umika iz mesta. }\end{array}$ & 23 & 33 & 24,5 & 13,5 & 6 & 2,47 & 1,16 \\
\hline Zaradi prireditev je več kriminala. & 14 & 32 & 27,5 & 23 & 3,5 & 2,7 & 1,08 \\
\hline $\begin{array}{l}\text { Zaradi prireditev je več prekomernega } \\
\text { pitja alkohola in uživanja mamil. }\end{array}$ & 3,5 & 15 & 27 & 41 & 13,5 & 3,46 & 1,02 \\
\hline Zaradi prireditev je več prometne gneče. & 1 & 4 & 11,5 & 52,5 & 31 & 4,09 & 0,82 \\
\hline $\begin{array}{l}\text { Zaradi prireditev je težje najti } \\
\text { parkirno mesto. }\end{array}$ & 1 & 4,5 & 12 & 43 & 39,5 & 4,15 & 0,88 \\
\hline $\begin{array}{l}\text { Zaradi prireditev je več gneče na } \\
\text { javnih površinah in javnih objektih. }\end{array}$ & 0,5 & 4 & 9,5 & 53,5 & 32,5 & 4,14 & 0,78 \\
\hline $\begin{array}{l}\text { Prireditve pripomorejo k višanju } \\
\text { cen dobrin in storitev. }\end{array}$ & 4,5 & 14 & 33 & 40,5 & 8 & 3,34 & 0,97 \\
\hline $\begin{array}{l}\text { Prireditve pripomorejo k višanju } \\
\text { vrednosti nepremičnin in stroškov } \\
\text { najema. }\end{array}$ & 6,5 & 19 & 42 & 25,5 & 7 & 3,07 & 0,99 \\
\hline
\end{tabular}


- med zaposlenimi in nezaposlenimi v turizmu,

- med sodelujočimi in ne sodelujočimi na prireditvah,

- glede na dolžino bivanja v občini in

- glede na povezanost med splošnim mnenjem o prireditvah in dojemanjem pozitivnih ter negativnih družbenih vplivov.

Najprej smo se osredotočili na razliko v dojemanju pozitivnih in negativnih vplivov med spoloma. Za izračun enostranskega t-testa dveh neodvisnih vzorcev smo uporabili tri spremenljivke; pozitivni vpliv, negativni vpliv in spol. Omenjeni test pokaže, ali obstaja statistično pomembna razlika v povprečju med dvema neodvisnima skupinama (anketirankami in anketiranci). Ugotovili smo, da imajo moški in ženske enako povprečno mnenje glede pozitivnega vpliva prireditev (oba $M=3,72$ ). Pri negativnem vplivu pa sta povprečji nekoliko različni, kar pomeni, da se ženske nekoliko bolj strinjajo, da imajo prireditve negativen vpliv $(M=3,46$; moški: $M=3,44)$. Ugotovili smo, da razlike med spoloma niso statistično značilne $(\alpha>0,05)$.

Sledila je primerjava dojemanja obeh vrst vplivov med prebivalci glede na njihovo območje bivanja. Uporabili smo analizo variance (ANOVA) in spremenljivke pozitivni, negativni vpliv ter kraj bivanja. $\mathrm{Z}$ analizo variance preverimo, ali so razlike med vzorci razložljive kot statistična odstopanja znotraj iste populacije. Razlika med ANOVO in t-testom je v tem, da lahko pri ANOVI računamo z več kot dvema aritmetičnima sredinama. Ugotovili smo, da se s pozitivnimi vplivi v povprečju najbolj strinjajo prebivalci predmestij $(M=3,73)$, najmanj pa prebivalci centra mesta $(M=3,6)$. Razlike med lokacijami bivanja niso statistično značilne $(\alpha>0,05)$. Obratno je pri negativnih vplivih prireditev, $s$ katerimi se prebivalci centra $\mathrm{v}$ povprečju najbolj strinjajo $(\mathrm{M}=3,79)$, najmanj pa prebivalci predmestij $(M=3,42)$, vendar razlike med skupinami tudi v tem primeru niso statistično značilne $(\alpha>0,05)$.

Nadalje smo se osredotočili na razlike med zaposlenimi v turizmu in tistimi, ki to niso ter njihovim dojemanjem pozitivnih in negativnih vplivov. Za izračun smo uporabili enostranski t-test za neodvisna vzorca, spremenljivke pozitivni, negativni vplivi in zaposlenost v turizmu. Ugotavljamo, da ni bistvene razlike $\mathrm{v}$ dojemanju pozitivnih in negativnih vplivov prireditev med zaposlenimi v turizmu in tistimi, ki to niso. $\mathrm{V}$ obeh primerih sta povprečji gotovo enaki, prav tako razlike med skupinama niso statistično značilne (obe $\alpha>0,05$ ).

Zanimalo nas je še, ali sodelovanje na prireditvah vpliva na dojemanje pozitivnih in negativnih vplivov prireditev. V izračun smo vključili spremenljivke pozitivni, negativni vpliv ter sodelovanje na prireditvah. Uporabili smo enostranski t-test za neodvisne vzorce. Ugotovili smo, da se sodelujoči na prireditvah v povprečju v večji meri strinjajo s pozitivnimi vplivi $(\mathrm{M}=4,00)$, medtem ko nesodelujoči nekoliko manj $(M=3,69)$, vendar pa razlike med njimi niso statistično značilne $(\alpha>0,05)$. Obratno je pri dojemanju negativnih vplivov, kjer se $\mathrm{v}$ večji meri $\mathrm{z}$ njimi strinjajo nesodelujoči $(M=3,46)$, kot sodelujoči $(\mathrm{M}=3,32)$. Ugotavljamo, da tudi v tem primeru razlike med skupinama niso statistično značilne $(\alpha>0,05)$.

Nadalje smo preverili, ali $z$ daljšo dobo bivanja v občini narašča tudi stopnja dojemanja negativnih vplivov prireditev. Uporabili smo spremenljivki negativni vpliv ter dolžina bivanja v občini, med katerima smo izračunali korelacijo s Paersonovim koeficientom. Korelacija v statistiki označi istočasno usklajenost pri variiranju (Knežević 2006, 143). Za uporabo Pearsonovega koeficienta morata biti vrednosti obeh spremenljivk številčni, število podatkov mora biti vsaj 30 , porazdelitve v spremenljivkah morajo biti simetrične in povezanost spremenljivk mora biti linearna. V našem primeru je korelacija med dolžino bivanja in negativnimi vplivi šibka $(0,05)$ in ni statistično značilna $(\alpha>0,05)$.

$\mathrm{Na}$ koncu smo preverili, ali anketiranci, ki imajo bolj pozitivno mnenje o prireditvah, dojemajo vplive bolj pozitivno in obratno. Uporabili smo spremenljivke pozitivni, negativni vpliv ter splošno mnenje o prireditvah. Za preverjanje omenjenih razlik, smo uporabili analizo variance (ANOVA). Ugotovili smo, da imajo anketiranci, ki radi obiskujejo prireditve, najbolj pozitivno mnenje $(M=3,94)$, v najmanjši meri pa se z njimi strinjajo tisti, ki prireditev ne marajo $(M=2,58)$. Razlike med skupinami so statistično značilne $(\alpha<0,05)$. Negativne vplive najbolj zaznavajo tisti, ki ne marajo prireditev $(M=3,98)$, najmanj pa tisti, ki jih imajo radi $(M=3,3)$. Tudi tukaj so razlike med skupinami statistično značilne $(\alpha<0,05)$. 


\subsection{Intervju}

Vsi trije predstavniki krajevnih skupnosti so izpostavili dobro sodelovanje $\mathrm{z}$ občino. Po njihovem mnenju občina ustrezno posreduje informacije in prireditve tudi finančno podpre v okviru razpoložljivih sredstev. Prav tako so intervjuvanci izpostavili prireditve, na katerih sodelujejo, in sicer gre za predstavitve krajevnih skupnosti in turističnih društev ob občinskem prazniku. S strani Turistične organizacije Koper smo dobili odgovor, da redno sodelujejo s krajevnimi skupnostmi s svetovanjem za organizacijo prireditev, pomoči pri trženju in promocijskih aktivnostih, sodelovanju pri izposoji opreme ter sofinanciranju tiskovin za namen oglaševanja prireditve.

Glede interesa za sodelovanje na prireditvah smo med posameznimi predstavniki prejeli različne odgovore. V Krajevni skupnosti Olmo-Prisoje ugotavljajo, da interesa praktično ni, saj nimajo turističnega društva ali drugih društev, ki bi izražala željo po prireditvah. Podobno ugotavljajo tudi v Krajevni skupnosti Boršt. Opažajo, da je z leti interesa krajanov manj. V Krajevni skupnosti Koper-center pa je nekaj zelo aktivno sodelujočih na področju prireditev. Predstavnica občine je dejala, da opažajo različno stopnjo angažiranosti krajanov, hkrati pa izpostavila dve prireditvi, na katerih najbolj intenzivno sodelujejo s krajevnimi skupnostmi in društvi. To sta prireditvi Koper na dlani in Istrska pustna povorka.

Vezano na število in kakovost prireditev v Krajevni skupnosti Boršt ugotavljajo, da je bilo nekoč več prireditev in so trajale dlje. Razlog vidijo v nedobičkonosnosti današnjih prireditev v primerjavi s preteklimi. Druga dva predstavnika sta mnenja, da so prireditve kakovostne in koristne, saj zadovoljujejo potrebe različnega ciljnega občinstva. V Krajevni skupnosti Olmo-Prisoje dodajajo, da je prireditev poleti premalo. Predstavnica občine pa ocenjuje, da je veliko kakovostnih prireditev in takih, ki imajo potencial to postati. $V$ prihodnje si želijo še bolj kakovostnih prireditev, zato si prizadevajo za krepitev kakovosti prireditev predvsem na podeželju.

Vsi trije intervjuvani prepoznavajo koristi prireditev. V Krajevni skupnosti Olmo-Prisoje jih vidijo kot zabavno in kulturno popestritev vsakdanjika, v Krajevni skupnosti Boršt menijo, da prireditve pripomorejo k prepoznavnosti in razvoju podeželja, v Krajevni skupnosti Koper-center pa jih opisujejo kot privlačnost za prihod turistov ter njihovo večjo potrošnjo. Predstavnica občine je zgoraj omenjenim koristim dodala še ohranjanje kulturne dediščine in avtentičnosti, pozitivno zunanjo podobo občine ter povezovanje podeželja in mesta.

Glede slabosti prireditev smo ugotovili, da se zaznava slabosti prireditev pri intervjuvancih stopnjuje glede na bližino organiziranih prireditev. Tako v Krajevni skupnosti Koper-center izpostavljajo, da je kar naporno tistim, ki živijo blizu dogajanja. V Krajevni skupnosti Olmo-Prisoje pa povedo, da imajo največ težav s hrupom v nočnih urah. V najbolj oddaljeni Krajevni skupnosti Boršt ne zaznavajo slabosti, saj je tam le malo prireditev, zato se je intervjuvanec osredotočil na tiste, ki jih zaznava v centru mesta. Izpostavil je smeti in gnečo ter ocenil, da turisti iz križark ne naredijo veliko finančnega učinka. Predstavnica občine je kot glavne slabosti izpostavila manjši pomen tradicije, saj organizatorji v želji po množični udeležbi na prireditvah vnašajo tuje prvine, ki ne sodijo v to okolje, nekatere prireditve pa se podvajajo. Ker se slabosti zavedajo, poudarjajo pomen usklajevanja med deležniki prireditev, saj si želijo pozitivnega dolgoročnega razvoja prireditev in s tem tudi turizma.

Vezano na nadaljnji razvoj prireditev v Krajevni skupnosti Olmo-Prisoje povedo, da so predlagali naj bi se zapuščen objekt INDE preoblikoval v mladinski center za prireditve, saj je nekoliko odmaknjen od spalnega naselja, vendar ga je občina prodala v gospodarske namene. V Krajevni skupnosti Boršt menijo, da bi se moral spremeniti način življenja in dojemanja sveta, da bi se ljudje zopet sproščeno zabavali in družili. V Krajevni skupnosti Koper-center podpirajo nadaljnji razvoj prireditev predvsem zaradi turizma, pod pogojem da bo njegov razvoj strateško zastavljen $\mathrm{z}$ vidika turistov in občanov, torej sprejemljiv za vse deležnike v procesu. Podobno meni predstavnica občine, saj podpira aktivno sodelovanje z vsemi deležniki prireditev. Želi si, da bi te bi bile časovno usklajene, predvsem pa da bi ohranjale tradicijo in avtentičnost, saj je to skladno s povpraševanjem. 
Vprašanje o vlogi Turistične organizacije Koper pri organizaciji prireditev je bilo zastavljeno samo predstavnici občine, ki meni, da ima ta več tozadevnih vlog. V osnovi deluje kot organizator (na primer Istrska pustna povorka, Koper na dlani, Sladka Istra) in kot soorganizator (Istrski maraton). Njene vloge se kažejo tudi v koordinaciji priprav na prireditev in deležnikov, promociji ter svetovanju organizatorjem pri pripravi prireditev. Mestna občina Koper vsako leto sofinancira številne prireditve preko javnega razpisa. V preteklosti so v Turistični organizaciji Koper zastavili projekt oživljanja dogajanja na koprskem podeželju zaradi zmanjšanja pomena tradicije, kot opažajo tudi v Krajevni skupnosti Boršt. Enako ugotavljajo, da med turisti in obiskovalci narašča zanimanje za pristno istrsko avtentičnost, zato so začeli z aktivnostmi obuditve prireditev s tako vsebino.

\section{Diskusija in ugotovitve}

V nadaljevanju izpostavljamo ugotovitve, do katerih smo prišli z empirično raziskavo in obdelavo podatkov iz kvantitativnega dela raziskave:

- Koprska/Rumena noč je močna asociacija na prireditve v občini, saj je omenjena tako v odgovorih prvega vprašanja ter največkrat omenjena prireditev pri vprašanju, kjer smo spraševali po prvi asociaciji na točno določeno prireditev v občini;

- več kot polovica anketirancev obišče nekaj tradicionalnih prireditev, ne pa vseh, torej so prireditve s strani domačinov dobro obiskane;

- $59 \%$ vseh anketirancev rado obiskuje prireditve in si jih želi tudi v prihodnje, kar pomeni, da domačini podpirajo razvoj prireditev;

- pri pozitivnih in negativnih družbenih vplivih je bilo zaznati največ strinjanja, kar pomeni, da so ponujene trditve vsebinsko ustrezno zajele že opredeljene vplive prireditev iz pregleda literature.

Statističnih razlik pri dojemanju vplivov prireditev nismo zaznali:

- med spoloma,

- glede na območje bivanja v občini,

- med zaposlenimi in nezaposlenimi v turizmu,

- med sodelujočimi in nesodelujočimi na prireditvah.

Dolžina bivanja v občini tudi ne vpliva na stopnjo dojemanja negativnih vplivov. Dojemanje družbenih vplivov je statistično značilno povezano s splošnim mnenjem o prireditvah.

Večina avtorjev se v svojih raziskavah osredotoča na statistične razlike med spoloma. Weaver in Lawton (2013) analizirata druge raziskave, vendar ugotavljata, da ne moreta potrditi statistične razlike med spoloma, saj so različni avtorji prišli do različnih zaključkov. V našem primeru ugotavljamo, da ni statističnih razlik med odgovori glede na spol.

McGehee in Andereck (2004) sta ugotovila, da vplive prireditev najbolj negativno dojemajo ljudje iz zaledja, Korça (1998) in Madrigal (1995) pa sta ugotovila, da so negativni vplivi najbolj izraženi med prebivalci centra mest. Belisle in Hoy (1980) nasprotno poudarjata, da so v centru mesta prebivalci bolj naklonjeni prireditvam. Sami smo prišli do ugotovitev, da so najbolj negativnega mnenja do prireditev tisti, ki živijo v centru mesta, vendar pa razlike med območji niso statistično značilne. V našem primeru si to razlagamo s tem, da se večina prireditev dogaja v centru mesta, zato je razumljivo, da se negativni vplivi tam intenzivneje občutijo.

Korça (1998) in Madrigal (1995) sta prišla do ugotovitve, da ljudje, ki delajo v turizmu prireditve vidijo bolj pozitivno kot ostali. Sami do takšnih rezultatov nismo prišli.

Po pregledu literature nismo našli primernih ugotovitev za primerjavo dojemanja vplivov med sodelujočimi in ne sodelujočimi na prireditvah. Pričakovali bi, da tisti, ki sodelujejo, tudi pozitivneje dojemajo vplive, vendar naša raziskava tega ni potrdila. 
Allen s sodelavci (1988), Perdue, Long in Kang (1995) ter Weaver in Lawton (2001) so prišli do ugotovitev, da je daljša doba bivanja na destinaciji povezana $\mathrm{z}$ večjo dojemljivostjo do negativnih vplivov prireditev. Vendar naša raziskava tega ni pokazala.

Edina statistično potrjena povezava se $\mathrm{v}$ naši raziskavi nanaša na dojemanje družbenih vplivov in splošnim mnenjem o prireditvah. Do podobnega rezultata je prišla tudi Goriškova $(2015,63)$, ki je v isti občini preučevala družbeno-kulturne vplive ladijskega turizma. Glede na to, da je naš anketni vprašalnik temeljil na njenem, lahko rezultata primerjamo. Ugotovili smo, da bolj pozitivno splošno mnenje o prireditvah kaže na bolj pozitivno dojemanje vplivov prireditev.

Lesjak, Podovšovnik in Uran Maravić (2014) so ugotovili, da Koprčani visoko vrednotijo pozitivne kulturne vplive športnih prireditev, kot negativne pa najbolj zaznavajo prometno gnečo in težave s parkirišči. Koderman (2014) je opozoril na potrebo po prireditvah, družabnih in kulturnih dogodkih, ki jo prebivalci izražajo v skoraj vseh soseskah občine. Podobno je Medarićeva (2014) izpostavila pomankanje ponudbe kulturnih dogodkov, zlasti v času izven sezone, kar zaznavajo prebivalci mestnega jedra. Izsledki navedenih študij, ki so bile izvedene na istem območju, so skladni z našimi rezultati.

V nadaljevanju so predstavljene ugotovitve o pridobljenih podatkih na podlagi strukturiranega intervjuja med predsedniki izbranih krajevnih skupnosti in predstavnico občine Koper. Ugotavljamo, da: - je sodelovanje med občino in krajevnimi skupnostmi pozitivno na vseh področjih, ne samo na področju prireditev;

- se interes krajanov za sodelovanje na prireditvah med posameznimi krajevnimi skupnostmi razlikuje;

- obstajajo kakovostne prireditve, vendar jih je manj kot nekoč, predvsem pa so krajše;

- prireditve prinašajo koristi krajevnim skupnostim, občini in njenim občanom;

- se zaznava slabosti prireditev stopnjuje glede na bližino organiziranih prireditev;

- vsi intervjuvanci podpirajo nadaljnji razvoj prireditev, vendar s poudarkom na strateško zastavljenem in usmerjenem razvoju, ki vključuje vse deležnike v procesu;

- Mestna občina Koper in Turistična organizacija Koper, kot njen del, dobro sodelujeta s posameznimi krajevnimi skupnostmi na vseh področjih. Menimo, da se sodelovanje med njimi lahko še izboljša $\mathrm{z}$ morebitnimi pogostejšimi neformalnimi srečanji, kjer bi stkali pristnejše odnose z željo po učinkovitejšem odzivu na določene skupne težave. Ugotavljamo tudi, da določen interes krajanov za sodelovanje na prireditvah obstaja, vendar se razlikuje glede na območje bivanja, zato menimo, da je koristno obuditi ta interes, s čimer bi lahko dosegli večjo vključenost občanov ter izboljšali splošno mnenje o prireditvah, kot tudi ponos domačinov. Izpostavimo lahko še dodatno prednost, ki je posledica povečanega interesa za sodelovanje. Ta se lahko kaže v novostih in idejah, ki jih je mogoče udejanjiti v sklopu nadaljnjega razvoja prireditev.

V občini se odvija nekaj izjemno kakovostnih prireditev, predvsem v mestnem jedru. Tradicionalne prireditve na podeželju nekoliko zamirajo, saj pri domačinih ni interesa za njihovo organizacijo, kar ugotavljajo tudi v Turistični organizaciji Koper. Zato so njihovi napori usmerjeni k spodbujanju nastanka ali obuditve prireditev na podeželju, kjer je več avtentičnih vsebin in tradicije. Obenem pa poskušajo omejiti vnos tujih prvin pri organizaciji tradicionalnih prireditev, ki ne odražajo pristnost lokalnega okolja.

Prireditve imajo prednosti in slabosti, ki se jih vsi respondenti zavedajo. Iz rezultatov anketnega vprašalnika in intervjujev izhaja, da je več koristi kot slabosti. To je dokaz, da je vizija razvoja prireditev dobro zasnovana in da jih prebivalci v veliki meri sprejemajo kot pozitivne tako zase kot za mesto. V prihodnje je po mnenju naših sogovornikov treba vselej spremljati odnos lokalne skupnosti, saj je njihova naklonjenost ključnega pomena za uspeh prireditev. To je skladno z ugotovitvami drugih avtorjev (McDonnell, Allen in O’Toole 1999; Derret v: Robinson, Wale in Dickson 2010; Bowdin s sodelavci 2011).

$\mathrm{Na}$ to se nanaša tudi mnenje o nadaljnjem razvoju prireditev v občini, kjer so intervjuvanci prepričani, da je treba razvoj v bodoče strateško zastaviti in usmeriti v skladu s pričakovanji lokalne skupnosti ter drugih deležnikov prireditev. Predstavnica občine poudarja, da sami prihodnost vidijo v aktivnem povezovanju lokalnih ponudnikov, saj oni s svojimi dejavnostmi v veliki meri predstavljajo avtentično istrsko doživetje. 
Na podlagi analize empiričnega dela smo prišli do splošne ugotovitve, da je velika večina prireditev dobro zasnovana in sprejeta med lokalno skupnostjo. $S$ tem ima občina možnosti za dolgoročno uspešen nadaljnji razvoj prireditev, ob predpostavki, da bo ta potekal usklajeno. Ugotavljamo tudi, da se veliko truda namenja opazovanju, spremljanju, predvidevanju ter načrtovanju vplivov, torej se deluje proaktivno, kar je nujno, če želi biti destinacija konkurenčna na turističnem trgu.

\section{Sklep}

Teoretski prispevek tega članka je sistematičen pregled virov s področja družbenih vplivov prireditev, zlasti v delu, ko se ugotavlja njihova kompleksnost, razumevanje in odziv menedžmenta. Hkrati so podane tudi praktične implikacije za upravljanje vplivov, kot tudi izhodišča za učinkovit dolgoročni razvoj prireditev v občini.

Večina anketirancev redno obiskuje prireditve in podpira njihov nadaljnji razvoj. Zato je treba nenehno skrbeti, da negativni vplivi ne presežejo pozitivne in s tem ogrozijo nadaljnji razvoj turizma. Raziskava je pokazala, kateri pozitivni in kateri negativni družbeni vplivi so bolj prepoznani s strani domačinov. V prihodnje je treba načrtovati ustrezne ukrepe in aktivnosti, da bi negativne zmanjšali in pozitivne povečali.

$\mathrm{Z}$ upoštevanjem priporočil bo občina lahko obogatila in dopolnila program prireditev, skladno s pričakovanji domačinov. Posledično se bo okrepila kakovost prireditev. V prihodnje lahko pričakujemo, da bo destinacija dolgoročno pridobila priložnost za doseganje konkurenčne prednosti na domačem in tujem trgu. Ponudba prireditev naj bo tako v prihodnje še bolj pestra in kakovostna, s poudarkom na rednem spremljanju zaznav vplivov turizma s strani lokalne skupnosti. Dobrodošlo bi bilo, da bi na občinski ravni skrbeli za povezovanje med organizatorji prireditev in obalnimi občinami ter enakomerno razporeditvijo prireditev prek celega leta, saj bo le tako ponudba prireditev postala celovita ter širše prepoznana. Ta del nalog in aktivnosti sodi v delokrog destinacijskega menedžmenta, ki ga v tem trenutku opravljajo lokalne turistične organizacije.

Raziskava ima določene omejitve, ki bi jih lahko pripisali času in sredstvom za izvedbo, kot tudi izvzetosti nekaterih deležnikov. Kvantitativna raziskava med prebivalci je bila izvedena v pomladnih mesecih, kar je lahko razlog za močnejše asociacije prireditev, ki so se odvijale v tistem obdobju oziroma za milejše dojemanje negativnih vplivov, saj takrat še ni tako pestrega programa prireditev, kot je v poletnih mesecih. Obenem sta bili raziskavi, tako kvantitativna kot kvalitativna, opravljeni na izbranem vzorcu in ne na celotni populaciji, kar nam do neke mere otežuje posploševanje rezultatov. V našo raziskavo tudi nismo vključili vseh deležnikov prireditev, ki smo jih prepoznali ob pregledu literature, zato v tem delu vidimo možnosti za nadaljnje poglobljeno raziskovanje. Vsekakor pa bi bilo $\mathrm{v}$ prihodnosti vredno preučiti zaznave obiskovalcev in turistov.

\section{Viri in literatura}

Allen, L., Long, P., Perdue, R., Keiselbach, S. 1988: The impact of tourism development on residents' perceptions of community. Journal of Travel Research 27-1. DOI: https://doi.org/10.1177/ 004728758802700104

Andersson, T., Lundberg, E. 2013: Commensurability and sustainability: triple impact assessments of a tourism event. Tourism Management 37. DOI: https://doi.org/10.1016/j.tourman.2012.12.015

Balduck, A. L., Maes, M., Buelens, M. 2011: The social impact of the Tour de France: Comparisons of residents' pre-and post-event perceptions. European Sport Management Quarterly 11. DOI: https://doi.org/10.1080/16184742.2011.559134 
Belisle, F., Hoy, D. 1980: The perceived impact of tourism by residents: a case study in Santa Marta, Colombia. Annals of Tourism Research 7-1. DOI: https://doi.org/10.1016/S0160-7383(80)80008-9

Bowdin, G., Allen, J., O’Toole, W., Harris, R., McDonnell, I. 2011: Events Management. Oxford.

Brown, S., Getz, D., Pettersson, R., Wallstam, M. 2015: Event evaluation: definitions, concepts and a state of the art review. International Journal of Event and Festival Management 6-2. DOI: https://doi.org/ 10.1108/IJEFM-03-2015-0014

Connell, J., Page, S. J., Meyer, D. 2015: Visitor attractions and events: Responding to seasonality. Tourism Management 46. DOI: https://doi.org/10.1016/j.tourman.2014.06.013

Fredline, L., Deery, M., Jago, L. 2006: Development of a Scale to Assess the Social Impacts of Tourism within Communities. Gold Coast.

Getz, D. 1997: Event Management and Event Tourism. New York.

Getz, D., Page, S. J. 2016: Progress and prospects for event, tourism research. Tourism Management 52. DOI: https://doi.org/10.1016/j.tourman.2015.03.007

Goldblatt, J. 2000: A Future for event management: the analysis of major trends impacting the emerging profession. Events beyond 2000: Setting the Agenda, 2. Proceedings of Conference on Event Evaluation, Research and Education. Sydney.

Goldblatt, J. J. (ur.) 2008: Special Events: The Roots and Wings of Celebration. Hoboken.

Goldblatt, J. J. 1997: Special Events. New York.

Gorišek, P. 2015: Analiza družbeno-kulturnih vplivov ladijskega turizma: primer Slovenije. Magistrsko delo, Ekonomska fakulteta Univerze v Ljubljani. Ljubljana.

Hall, M., Lew, A. A. 2009: Understanding and Managing Tourism Impacts: An Integrated Approach. New York. Jones, C. 2001: Mega-events and host-region impacts: determining the true worth of the 1999 Rugby World Cup. International Journal of Tourism Research 3-3. DOI: https://doi.org/10.1002/jtr.326

Kariel, H. G., Kariel, P. E. 1982: Socio-Cultural Impact of Tourism: An Example from the Austrian Alps. Geografiska Annaler: Series B, Human Geography 64-1. DOI: https://doi.org/10.2307/490903

Knežević, M. 2006: Statistika z uporabo računalnika. Portorož.

Koderman, M. 2014: Zadovoljstvo prebivalcev mesta Koper s kakovostjo bivalnega okolja v izbranih soseskah. Koper živi? Vključevanje prebivalcev v urejanje javnega prostora. Koper.

Korça, P. 1998: Resident perceptions of tourism in a resort town. Leisure Sciences 20-3. DOI: https://doi.org/ 10.1080/01490409809512280

Lesjak, M., Podovšovnik, E., Uran Maravić, M. 2014: The perceived social impacts of the EuroBasket 2013 on Koper residents. Academica Turistica 7-2.

Madrigal, R. 1995: Residents' perceptions and the role of government. Annals of Tourism Research 22-1. DOI: https://doi.org/10.1016/0160-7383(94)00070-9

Mason, P. 2003: Tourism Impacts, Planning and Management. Medmrežje: http://www.mu.edu.et/ iphc/images/liblary/Heritage/Heritage_Culture_and_Tourism/Tourism_Impacts_Planing_ devet.pdf (1.3.2017).

McDonnell, I., Allen, J., O’Toole, W. 1999: Festival and Special Event Management. Brisbane.

McGehee, N., Andereck, K. 2004: Factors predicting rural residents' support of tourism. Journal of Travel Research 43-2. DOI: https://doi.org/10.1177/0047287504268234

Medarić, Z. 2014: Pogledi prebivalcev na življenje v starem mestnem jedru Kopra. Koper živi? Vključevanje prebivalcev v urejanje javnega prostora. Koper.

Mesec, B. 1998: Uvod v kvalitativno raziskovanje v socialnem delu. Ljubljana.

Perdue, R., Long, P., Kang, Y. 1995: Resident support for gambling as a tourist development strategy. Journal of Travel Research 34-2. DOI: https://doi.org/10.1177/004728759503400203

Robinson, P., Wale, D., Dickson, G. 2010: Events Management. Wallingford.

Schlenker, K., Foley, C., Getz, D. 2010: ENCORE Festival and Event Evaluation Kit: Review and Redevelopment. Medmrežje: https://pdfs.semanticscholar.org/b8e4/7026370d51714a6262 c66fb9748e 0532ec9e.pdf (20.12.2017). 
Sharpley, R. 2014: Host perceptions of tourism: A review of the research. Tourism Management 42. DOI: https://doi.org/10.1016/j.tourman.2013.10.007

Shone, A., Parry, B. 2010: Successful Event Management: A Practical Handbook. Andover.

Sikošek, M. 2010: Management prireditev: organizacija študentskih prireditev. Koper:.

Statistični urad Republike Slovenije. Medmrežje: http://www.stat.si (13.3.2017).

Tosun, C. 2002: Host perceptions of impacts, a comparative tourism study. Annals of Tourism Research 29-1. DOI: https://doi.org/10.1016/S0160-7383(01)00039-1

Vodeb, K. 2014: Turistična destinacija: sodobna obravnava koncepta. Koper.

Watt, D. C. 1998: Event Management in Leisure and Tourism. Harlow.

Weaver, D., Lawton, L. 2001: Resident perceptions in the urban-rural fringe. Annals of Tourism Research 28-2. DOI: https://doi.org/10.1016/S0160-7383(00)00052-9

Weaver, D. B., Lawton, L. J. 2013: Resident perceptions of a contentious tourism event. Tourism Management 37. DOI: https://doi.org/10.1016/j.tourman.2013.01.017

Wilson, J., Shone, M. C., Simmons, D. G., Stewart, E. 2015: Making waves: Examining the interface between cruise tourism and destination community in Akaroa, New Zealand. Tourism in Marine Environments 10, 3-4. DOI: https://doi.org/10.3727/154427315X14181438892856

Yuan, Y. Y. 2013: Adding environmental sustainability to the management of event tourism. International Journal of Culture, Tourism and Hospitality Research 7-2. DOI: https://doi.org/10.1108/ IJCTHR-04-2013-0024

Yürük, P., Akyol, A., Şimşek, G. G. 2017: Analyzing the effects of social impacts of events on satisfaction and loyalty. Tourism Management 60. DOI: https://doi.org/10.1016/j.tourman.2016.12.016

Zhou, Y. J., Ap, J. 2009: Residents perceptions towards the Impacts of the Beijing 2008 Olympic Games. Journal of Travel Research 48-1. DOI: https://doi.org/10.1177/0047287508328792

\section{Summary: Social impacts of events in Municipality of Koper}

(translated by Emanuela Malačič Kladnik)

Events are very important for tourists, locals and the host destination in general. From the local inhabitants' perspective, they bring social and personal advantages. For tourists, they may represent the reason for visiting a destination or prolonging their vacation. Especially in destinations with high seasonality, events may play the important role of a tourist attraction, which motivates visitors to come out of peak seasons or generally prolongs their stay. It all benefits the host destination, helping it build its promotion and image, especially if it hosts events with elements of local tradition that are well accepted and visited. Therefore, events serve many functions: tourist, cultural, economic, social, and political. They can sustain the local identity, and enhance recreational and social cohesion, which leads to cultural and social progress. Social impacts of events are of considerable importance for constructive and sustainable tourism development of a destination. Understanding the host communities' perceptions of tourism and its impacts provides a reliable tool for management to harmonize, balance and nurture the relationships among the main stakeholders at the destination. It empowers destination management to plan and develop the destination in accordance with the communities' pace and expectations, and optimizing their well-being by minimizing the costs of tourism development.

The social impact of events as a research topic has been an emerging issue in tourism for over twenty years and recently also in domestic scientific literature. In recent years, the Municipality of Koper put a greater emphasis on social events, so our goal was to study their social impact. Simultaneously, Koper has the ambition to become a tourist destination with high standards of tradition, authenticity and sustainability, which determines carefully planned, designed and provided destination experiences. In this context, we believe that the social impact of events play a very important role in determining the local community's perception of tourism. The scientific research all over the world confirms that 
community's attitude towards tourism plays a crucial role in tourist satisfaction with the destination and its success. These were the main motives for this research, to shed some light on issues of sustainable development of events in the emerging tourist destination of Koper. The aim of this paper was to explore the social impact of events, hosted in the Municipality of Koper, by employing quantitative and qualitative research methods. In May and June 2017, we conducted a survey among the local residents and an in-depth structured interview with the representatives of three local communities and a representative of the Municipality of Koper in the field of tourism office.

The findings showed that the local community supports the development of events; that the events revive the city's atmosphere and enhance the development of tourism. There is a high awareness of the importance of balanced strategic development and participation of all stakeholders. Our findings showed that the social impact depends on the general opinion about the events in the Municipality of Koper. We have recorded a high level of awareness of the local community about the impacts and the importance of harmonious relationships among the stakeholders regarding event development and its sustainability. The obtained results helped us shape the starting points for management decision process regarding the development of events in the Municipality of Koper in accordance with the local community's expectations. At the same time, considering our findings in comparison with other studies, we may conclude that the social impact significantly determines the destination's development stage, conditioned by a variety of factors and circumstances of the host destination.

Further research of the topic considering other stakeholders' perspective and perception of social impacts of events might provide a deeper insight and reliable foundations for optimising future development of events ensuring the well-being of all participants. 